\title{
Estimating particle export flux from satellite observations: challenges associated with spatial and temporal decoupling of production and export
}

\author{
Dennis J. McGillicuddy, Jr. ${ }^{\mathrm{a}}$ \\ Laure Resplandy ${ }^{\mathrm{b}}$ \\ Marina Lévy ${ }^{\mathrm{c}}$ \\ Manuscript submitted to Journal of Marine Research \\ Volume of The Sea in honor of James J. McCarthy
}

May 1, 2019

${ }^{\mathrm{a}}$ Department of Applied Ocean Physics and Engineering, Woods Hole Oceanographic Institution, Woods Hole, MA 02543, USA. Tel: 508-289-2683 Fax: 508-457-2194 Email:

dmcgillicuddy@whoi.edu (Corresponding Author).

${ }^{b}$ Princeton University, Geosciences Department, Princeton Environmental Institute, Princeton, NJ 08544, USA.

'Sorbonne Université, CNRS, IRD, MNHN, LOCEAN-IPSL, Paris, France. 


\begin{abstract}
Recent studies have suggested that accurate predictions of particle export flux can be derived from satellite-based estimates of phytoplankton biomass and net primary production (NPP), combined with models of the food web. We evaluate the performance of this approach using the output of a high-resolution basin-scale coupled physical-biogeochemical model. There is tight correlation between the annual mean export flux simulated by the biogeochemical model and that predicted by the satellite-based algorithm driven by NPP from the model. Although the satellite-based approach performs well on the annual average, there are significant departures during the course of the year, particularly in spring. NPP and export flux can also become decoupled at the mesoscale, when the dynamics of fronts and eddies cause export to be displaced in space and/or time from the productivity event generating the particulate material. These findings have significant implications for the design of field studies aimed at reducing uncertainties in estimates of export flux.
\end{abstract}

Key Words: Export flux, primary production, models, remote sensing. 


\section{Introduction}

Improvements in remote sensing technology have led to increasingly sophisticated retrievals of surface ocean bio-optical properties, including not only chlorophyll absorption but also particulate backscatter and net primary production (NPP) (Behrenfeld et al., 2005). These capabilities have facilitated novel approaches to estimating biogeochemical fluxes from satellite observations. In one such application, Siegel et al. (2014) combine satellite-based estimates of phytoplankton biomass and NPP with a food web model to predict the gravitational export flux of particles, hereafter referred to as simply “export flux” (Figure 1a). Initial results of this approach are encouraging, insofar as the model predicts large scale trends in export flux among the relatively few places in the world ocean where particle flux data are sufficient to constrain the model (Figure 1b).

Model-based frameworks offer a useful complement to evaluating such algorithms, insofar as they provide an internally consistent set of four-dimensional (space-time) fields that can be sampled without error at arbitrary resolution as fine as the native grid. This provides the opportunity to extract inputs to a satellite-based algorithm from a coupled physicalbiogeochemical model solution, predict export using the satellite-based algorithm, and then compare with the actual export predicted by the biogeochemical model. Of course, the efficacy of this approach depends on the degree to which the biogeochemical model is an accurate representation of the real ocean. Herein we use a high-resolution biogeochemical model configured in an idealized geometry of the North Atlantic Ocean (Lévy et al., 2010). Despite its idealized geometry, the model is able to capture key aspects of observations of export flux (Resplandy et al., 2012). Although it is clearly not a perfect model, it offers a framework in 
which to investigate the time and space scales in which NPP and export are coupled and decoupled.

\section{Methods}

The biogeochemical model is based on the primitive equation ocean circulation model NEMO (Nucleus for European Modeling of the Ocean) (Madec, 2008). The horizontal grid resolution of the physical model is $1 / 54^{\circ}$, which permits description of the mesoscale and submesoscale features of the flow with an effective resolution of $1 / 9^{\circ}$ (Lévy et al., 2012). The biogeochemical model is run offline at $1 / 9^{\circ}$ resolution with archived fields coarsened from the $1 / 54^{\circ}$ model. There are 30 vertical levels. The model domain is a rectangle of dimensions 2000 $\mathrm{km} \times 3000 \mathrm{~km}$, of $4 \mathrm{~km}$ depth, rotated by $45^{\circ}$ on the beta-plane, with closed boundaries and forced at the surface with seasonal buoyancy fluxes and wind. This configuration features a seasonally varying, semi-realistic Northwest Atlantic with a baroclinically unstable jet (the model's Gulf Stream) separating a warm, oligotrophic subtropical gyre south of the jet from a colder and more productive subpolar gyre north of it (see Lévy et al. 2010 and Lévy et al. 2012 for full details on the model). Instability processes lead to mesoscale turbulence characterized by a large number of interacting mesoscale eddies and submesoscale fronts. Coupled to this physical model is an ecosystem/biogeochemistry model "LOBSTER” based upon a phytoplanktonzooplankton-detritus-ammonium-nitrate-labile DOM nitrogen cycle model with modules for $\mathrm{CO}_{2}$ air-sea fluxes and ${ }^{234}$ Th scavenging and export (Karleskind et al., 2011; Lévy et al., 2012; Resplandy et al., 2009; Resplandy et al., 2012).

Our satellite-based approach follows Siegel et al. (2014), in which the total export from the euphotic zone (TotEZ) is the sum of algal (AlgEZ) and zooplankton (FecEZ) contributions. 
AlgEZ is a constant fraction of net primary production by large phytoplankton (AlgEZ $=f_{\text {Alg }}$ * $\mathrm{NPP}_{\mathrm{M}}$ ), whereas FecEZ is predicted by a food web model that includes small and large phytoplankton as well as microzooplankton and mesozooplankton.

The LOBSTER model distinguishes between new production (NP) based on nitrate and regenerated production (RP) based on ammonium. It includes only one phytoplankton component and one zooplankton component, but it does explicitly resolve two size classes of sinking detrital particles: small (SD) and large (LD). We therefore approximate the Siegel et al. (2014) model as:

$$
\begin{aligned}
& \mathrm{NPP}_{\text {LOBSTER }}=\mathrm{NP}+\mathrm{RP} \\
& \text { TotEZ } \\
& \text { LOBSTER } \\
& =\mathrm{f}_{\text {LOBSTER }} * \mathrm{NPP}_{\text {LOBSTER }}
\end{aligned}
$$

where $\mathrm{f}_{\text {LOBSTER }}$ is the proportion of $\mathrm{NPP}_{\text {LOBSTER }}$ that is exported through gravitational sinking of particles, roughly analogous to $f_{\text {Alg }}$ in the Siegel et al. (2014) model. The prediction of TotEZ $Z_{\text {LOBSTER }}$ can be tested with the explicitly simulated export flux:

$$
\text { Export }_{\text {LOBSTER }}=w_{S D} S D+w_{L D} L D
$$

where $w_{S D}$ and $w_{L D}$ are the sinking speeds of small $\left(4 \mathrm{~m} \mathrm{~d}^{-1}\right)$ and large (50-200 $\left.\mathrm{m} \mathrm{d}^{-1}\right)$ detritus, respectively (Resplandy et al., 2012). The fractional error can thus be computed

$$
\varepsilon=\frac{\text { TotEZ }_{L O B S T E R}-\text { Export }_{L O B S T E R}}{\text { Export }_{\text {LOBSTER }}}
$$


Because of the differences in the underlying biological formulations of the satellite-based algorithm and biogeochemical model, this does not constitute an explicit test of the Siegel et al. (2014) algorithm. Rather, these model-based comparisons provide a means to evaluate the approach of estimating export fluxes from surface properties (namely NPP) in a framework in which the inputs and outputs are known with certainty. As such, this analysis is intended to provide insight into the processes by which export can be coupled and/or decoupled with surface NPP, as well as the space and time scales over which the satellite-based approach applies.

\section{Annual mean fluxes and seasonal variation}

Annual mean NPP and export simulated by the LOBSTER model reflect expected large scale patterns, with higher values in the subpolar gyre and lower values in the subtropics (Figure 2, top row). There is tight correlation between the annual mean export flux in the model and that estimated with the satellite-based approach (Figure 3a). These results constrain the parameter $\mathrm{f}_{\text {LOBSTER }}$ in Equation (2) above, facilitating explicit prediction of TotEZ $Z_{\text {LOBSTER }}$ from $\mathrm{NPP}_{\text {LOBSTER }}$. Note that the magnitude of the annual mean export ratio $\mathrm{f}_{\text {LOBSTER }}$ is relatively high in this model, with a mean value of 0.52 .

Comparisons between daily averages of export and NPP reveal considerably more scatter than the annual mean values (Figure 3b). Much of this scatter is associated with the spring bloom (Figure 3c), as the correlation is much tighter in the late summer (Figure 3d). Statistics of

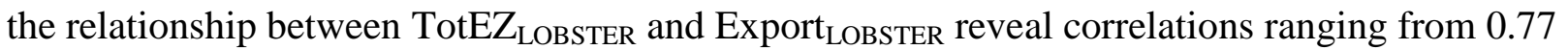
to 0.99 (Table 1). Despite this high correlation, the fractional error characteristics at any one point can be quite severe, ranging from over-predictions by a factor of 100 to under-predictions 
by a factor of more than 4000 . The latter are associated with cases of very low export, such that the denominator of Equation (4) is close to zero.

\section{Mesoscale variation}

Springtime snapshots of NPP and export reveal rich mesoscale variability (Figure 2, middle and lower columns). In fact, many of the outliers in the NPP vs. export relationship are associated with fronts and eddies. To get a sense of how mesoscale dynamics can decouple NPP and export, we examine a zoomed-in view of a particular event (Figures 4, 5).

On April 7 an anticyclonic eddy at ca. $33^{\circ} \mathrm{N}, 76^{\circ} \mathrm{W}$ with an anomalously deep mixed layer (Dufois et al., 2016; Gaube et al., 2019; Hausmann et al., 2017) has recently spawned from the front to the north. In the inner core of the eddy, the mixed layer depth exceeds $200 \mathrm{~m}$, which is sufficiently deep to entrain high-nitrate water from the nutricline, stimulate primary production, and elevate export, even in the early stages of this eddy induced bloom. By April 27, the mixed layer has shoaled to above $200 \mathrm{~m}$ where it is no longer in contact with the nutricline. Although this ends the phase of new production in this eddy-induced bloom, regenerated production and export continue to be enhanced. By May 7, the mixed layer has shoaled to ca. 45 $\mathrm{m}$ at eddy center, reducing the amplitude of the mesoscale variation in mixed layer depth to ca. $15 \mathrm{~m}$. Both NPP and export decline relative to their values on April 27, but the decline in NPP is more precipitous. As such, the enhanced export in the core of the eddy is identified as an outlier in the NPP vs. export relationship (black hatching in Figure 4). This is a direct result of the temporal decoupling in production and export associated with the eddy-induced bloom. It is interesting to note that there is spatial decoupling as well. From a Lagrangian perspective, the 
eastward propagation of the eddy feature results in export of material more than $200 \mathrm{~km}$ from the point of origin of the eddy.

\section{Conclusions}

Prediction of export flux from satellite observations is appealing for a number of reasons, not the least of which is the spatial and temporal coverage of the surface ocean surface properties provided by remote sensing (Siegel et al., 2014). Testing of such models presents a formidable challenge, insofar as the spatial and temporal scales accessible with in situ observations is much more limited. Ongoing efforts such as the Export Processes in the Ocean from Remote Sensing (EXPORTS) program (Siegel et al., 2016) seek to expand the observational basis for such approaches.

Herein we offer a model-based framework to assess the degree of coupling between NPP (observable by satellite) and export. On an annual mean basis, export is well correlated with NPP and robust predictions can be made on a point-by-point basis. However, strong seasonality of the temperate ocean creates temporal decoupling between production and export on seasonal time scales, and the quality of monthly predictions is substantially degraded over large regions of the ocean during the spring bloom. Mesoscale flows also introduce perturbations to the system, creating hotspots in productivity for which the subsequent export is spatially and temporally displaced from the point of origin. Despite the relatively fine resolution of the present model, we expect even finer scale fluctuations in export flux associated with the submesoscale (Estapa et al., 2015; Omand et al., 2015; Stukel et al., 2017). Moreover, treatment of subduction of both particulate and dissolved materials will be required for more complete models of total export flux (Boyd et al., 2019; Resplandy et al., submitted). In any case, the present results highlight the 
wide range of space and time scales that must be resolved in order to evaluate satellite-based predictions of export flux.

\section{Acknowledgments}

DJM gratefully acknowledges NASA grant NNX16AR50G as well as support from NSF. LR is funded by NASA EXPORTS awards 80NSSC17K0555 and NNX16AR50G. ML is supported by Centre National d'Etudes Spatiales (CNES) and by the French Agence Nationale de la Recherche award SOBUMS award ANR-16-CE01-0014. We thank Valery Kosnyrev for his excellent analysis and visualization of the results presented herein. 


\section{References}

Behrenfeld, M.J., Boss, E., Siegel, D.A., Shea, D.M., 2005. Carbon-based ocean productivity and phytoplankton physiology from space. Global Biogeochemical Cycles 19, GB1006.

Boyd, P.W., Claustre, H., Lévy, M., Siegel, D.A., Weber, T., 2019. Multi-faceted particle pumps drive carbon sequestration in the ocean. Nature 568, 327-335.

Dufois, F., Hardman-Mountford, N.J., Greenwood, J., Richardson, A.J., Feng, M., Matear, R.J., 2016. Anticyclonic eddies are more productive than cyclonic eddies in subtropical gyres because of winter mixing. Science Advances 2.

Estapa, M.L., Siegel, D.A., Buesseler, K.O., Stanley, R.H.R., Lomas, M.W., Nelson, N.B., 2015. Decoupling of net community and export production on submesoscales in the Sargasso Sea. Global Biogeochemical Cycles 29, 1266-1282.

Gaube, P., J. McGillicuddy Jr, D., Moulin, A.J., 2019. Mesoscale Eddies Modulate Mixed Layer Depth Globally. Geophysical Research Letters 46, 1505-1512.

Hausmann, U., McGillicuddy, D.J., Marshall, J., 2017. Observed mesoscale eddy signatures in Southern Ocean surface mixed-layer depth. Journal of Geophysical Research: Oceans 122, 617635.

Karleskind, P., Lévy, M., Memery, L., 2011. Subduction of carbon, nitrogen, and oxygen in the northeast Atlantic. Journal of Geophysical Research: Oceans 116, C02025.

Lévy, M., Iovino, D., Resplandy, L., Klein, P., Madec, G., Tréguier, A.M., Masson, S., Takahashi, K., 2012. Large-scale impacts of submesoscale dynamics on phytoplankton: Local and remote effects. Ocean Modelling 43-44, 77-93.

Lévy, M., Klein, P., Tréguier, A.M., Iovino, D., Madec, G., Masson, S., Takahashi, K., 2010. Modifications of gyre circulation by sub-mesoscale physics. Ocean Modelling 34, 1-15.

Madec, G., 2008. Nemo ocean engine. Note du Pole de modelisation de l’Institut Pierre-Simon Laplace 27, 1-217.

Omand, M.M., D’Asaro, E.A., Lee, C.M., Perry, M.J., Briggs, N., Cetinić, I., Mahadevan, A., 2015. Eddy-driven subduction exports particulate organic carbon from the spring bloom. Science 348, 222-225.

Resplandy, L., Lévy, M., d'Ovidio, F., Merlivat, L., 2009. Impact of submesoscale variability in estimating the air-sea $\mathrm{CO}_{2}$ exchange: Results from a model study of the POMME experiment. Global Biogeochemical Cycles 23, doi: 10.1029/2008gb003239.

Resplandy, L., Lévy, M., McGillicuddy, D.J., submitted. Effects of eddy-driven subduction on ocean biological carbon pump. Global Biochemical Cycles. 
Resplandy, L., Martin, A.P., Le Moigne, F., Martin, P., Aquilina, A., Mémery, L., Lévy, M., Sanders, R., 2012. How does dynamical spatial variability impact ${ }^{234}$ Th-derived estimates of organic export? Deep Sea Research I 68, 24-45.

Siegel, D.A., Buesseler, K.O., Behrenfeld, M.J., Benitez-Nelson, C.R., Boss, E., Brzezinski, M.A., Burd, A., Carlson, C.A., D'Asaro, E.A., Doney, S.C., Perry, M.J., Stanley, R.H.R., Steinberg, D.K., 2016. Prediction of the Export and Fate of Global Ocean Net Primary Production: The EXPORTS Science Plan. Frontiers in Marine Science 3.

Siegel, D.A., Buesseler, K.O., Doney, S.C., Sailley, S.F., Behrenfeld, M.J., Boyd, P.W., 2014. Global assessment of ocean carbon export by combining satellite observations and food-web models. Global Biogeochemical Cycles 28, 181-196.

Stukel, M.R., Aluwihare, L.I., Barbeau, K.A., Chekalyuk, A.M., Goericke, R., Miller, A.J., Ohman, M.D., Ruacho, A., Song, H., Stephens, B.M., Landry, M.R., 2017. Mesoscale ocean fronts enhance carbon export due to gravitational sinking and subduction. Proceedings of the National Academy of Sciences 114, 1252-1257. 


\begin{tabular}{|l|c|c|c|c|c|}
\hline & & & \multicolumn{4}{|c|}{ Fractional error characteristics } \\
\hline & $\mathrm{f}_{\text {LOBSTER }}$ & $\mathrm{r}^{2}$ & Min & Max & Std Dev \\
\hline Annual mean & 0.52 & 0.99 & -0.30 & 0.98 & 0.18 \\
\hline Daily averages & 0.53 & 0.86 & -4322.4 & 106.5 & 2.38 \\
\hline January & 0.47 & 0.97 & -4322.4 & 9.23 & 8.12 \\
\hline February & 0.47 & 0.96 & -397.3 & 106.5 & 0.74 \\
\hline March & 0.51 & 0.92 & -8.4 & 32.9 & 0.38 \\
\hline April & 0.70 & 0.79 & -0.7 & 21.0 & 0.68 \\
\hline May & 0.57 & 0.77 & -2.0 & 21.1 & 0.57 \\
\hline June & 0.45 & 0.96 & -0.8 & 2.8 & 0.35 \\
\hline July & 0.44 & 0.98 & -0.7 & 3.5 & 0.31 \\
\hline August & 0.45 & 0.97 & -0.9 & 7.3 & 0.30 \\
\hline September & 0.47 & 0.97 & -0.7 & 8.3 & 0.31 \\
\hline October & 0.50 & 0.95 & -0.7 & 7.1 & 0.29 \\
\hline November & 0.50 & 0.94 & -0.8 & 5.2 & 0.28 \\
\hline December & 0.45 & 0.93 & -12.2 & 6.8 & 0.30 \\
\hline
\end{tabular}

Table 1. Statistics of the satellite-based algorithm applied to the biogeochemical model. The first two columns report the correlation between TotEZ $Z_{\text {LOBSTER }}$ (Equation 2) and Export LOBSTER (Equation 3) along with the slope of the best fit line in each case. The fractional error

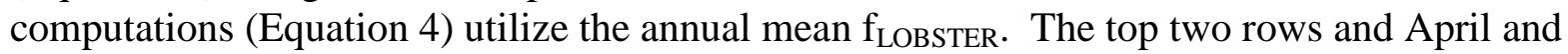
August cases correspond directly to Figure 3a-d, respectively. As in Figure 3c and 3d, all of the monthly cases reported here are use daily average values. 
(a)

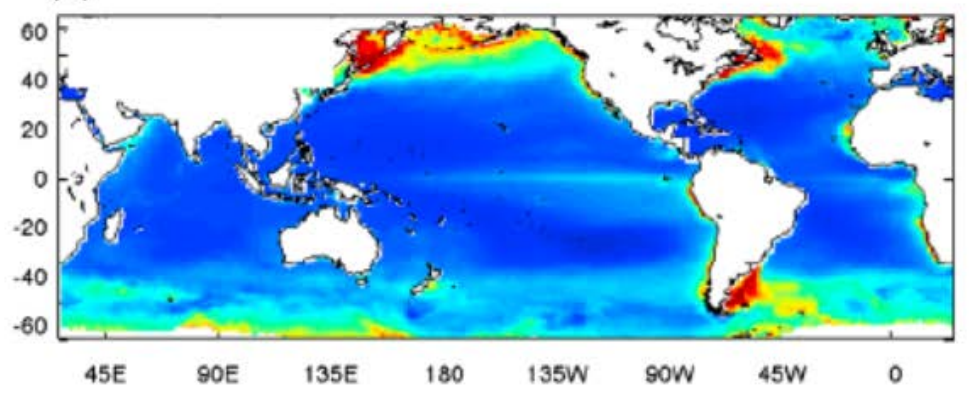

(b)

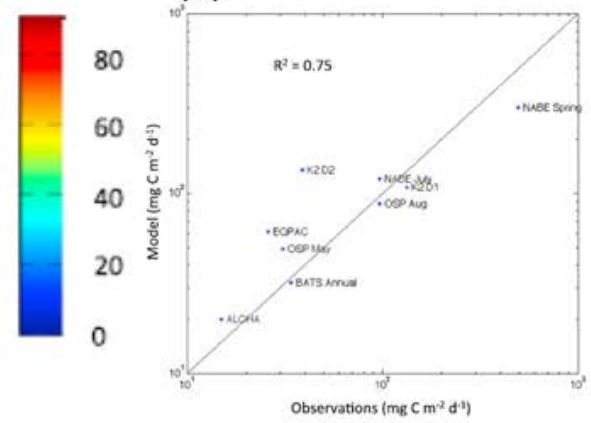

Figure 1. Results of the Siegel et al. (2014) export model. (A) Global distribution of annual

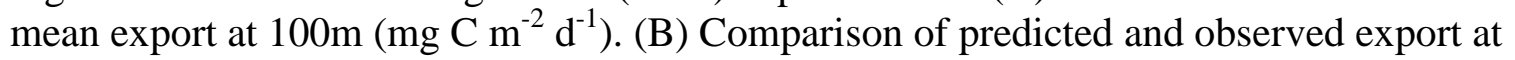
various sites. Figures 5c and $6 \mathrm{~b}$ from Siegel et al. (2014) reproduced with permission. 

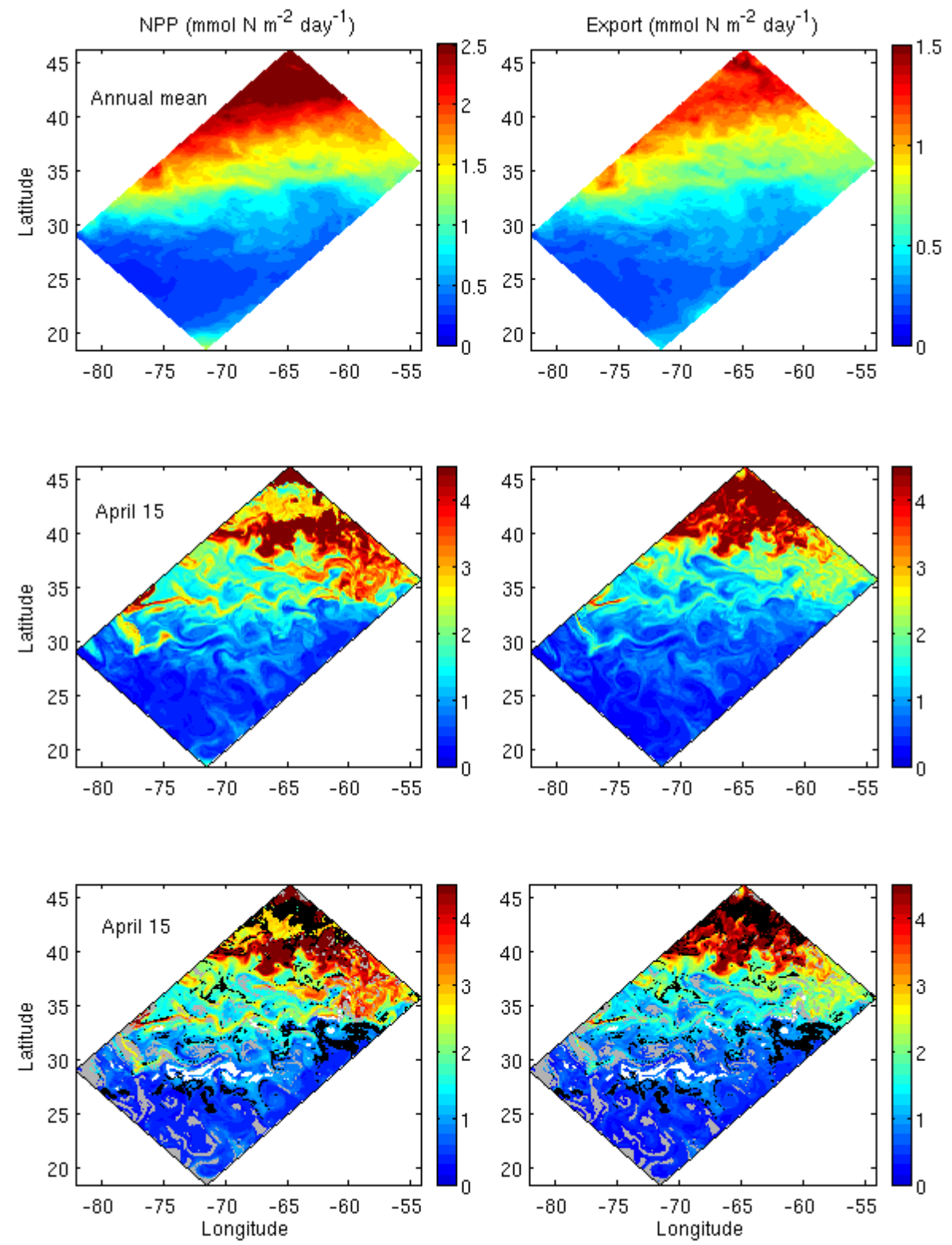

Figure 2. Net primary production integrated over the euphotic zone (135 m) (left column) and export (right column). Top row: annual means. Middle row: a snapshot on April 15. Bottom row: same as the middle row, with the extrema in the export versus NPP relationship (binned at increments of $0.5 \mathrm{~mol} \mathrm{~N} \mathrm{~m}^{-2} \mathrm{~d}^{-1}$ ) shown in black (highest $10 \%$ ) and gray (lowest $10 \%$ ). Areas where the mixed layer depth exceeds the euphotic zone depth $(135 \mathrm{~m})$ are indicated in white. Note that a strip of 20 points has been removed along the lateral boundaries, so the area shown here is slightly smaller than the full domain. 
(a)
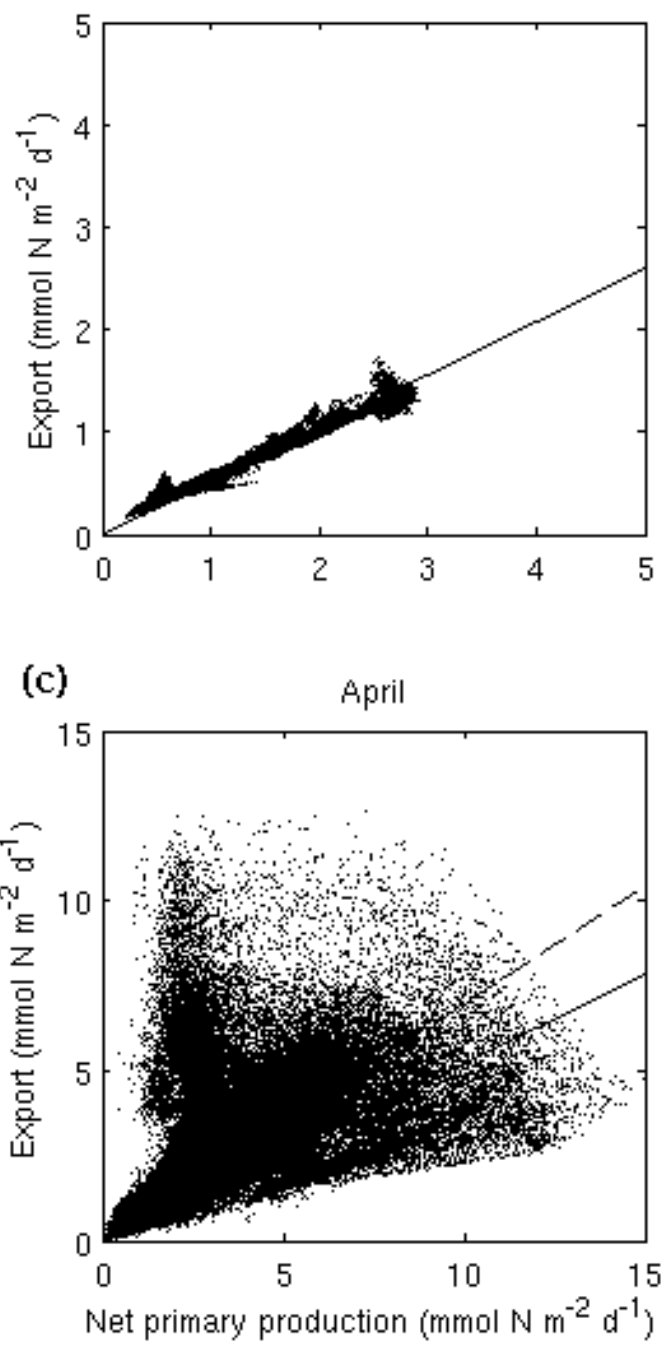

(b)

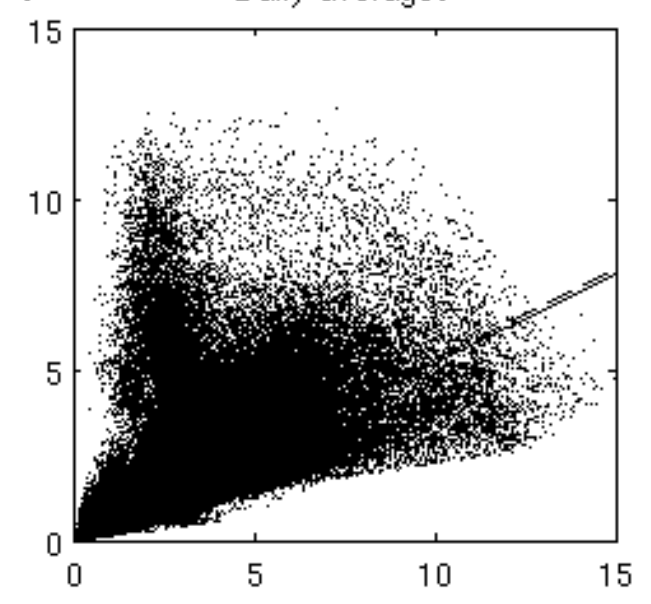

(d)

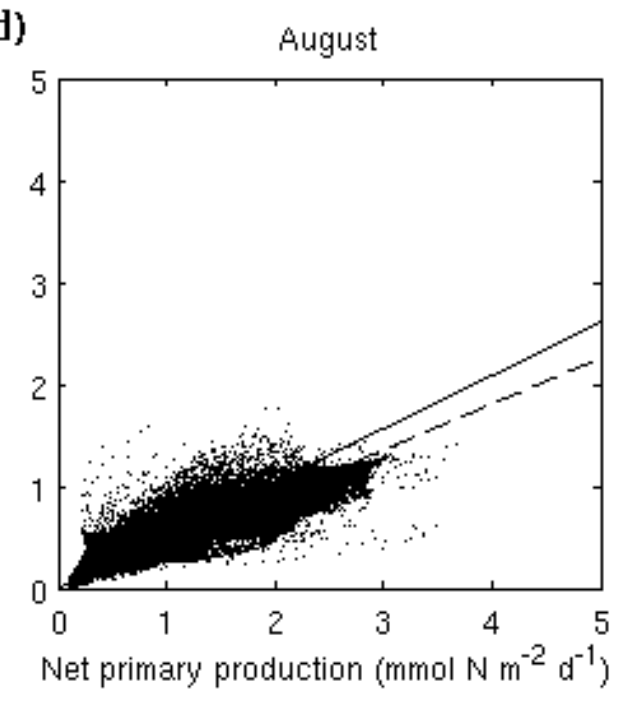

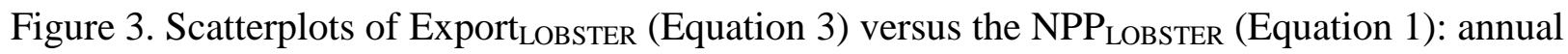
mean (a), and daily averages for the entire year (b), April (c), and August (d). The solid line in the annual mean case (panel a) is replotted in panels b-d for comparison with the linear fit to the other cases (dashed lines). The slope of these linear fits is reported in Table 1 as $f_{\text {LOBSTER. }}$ 

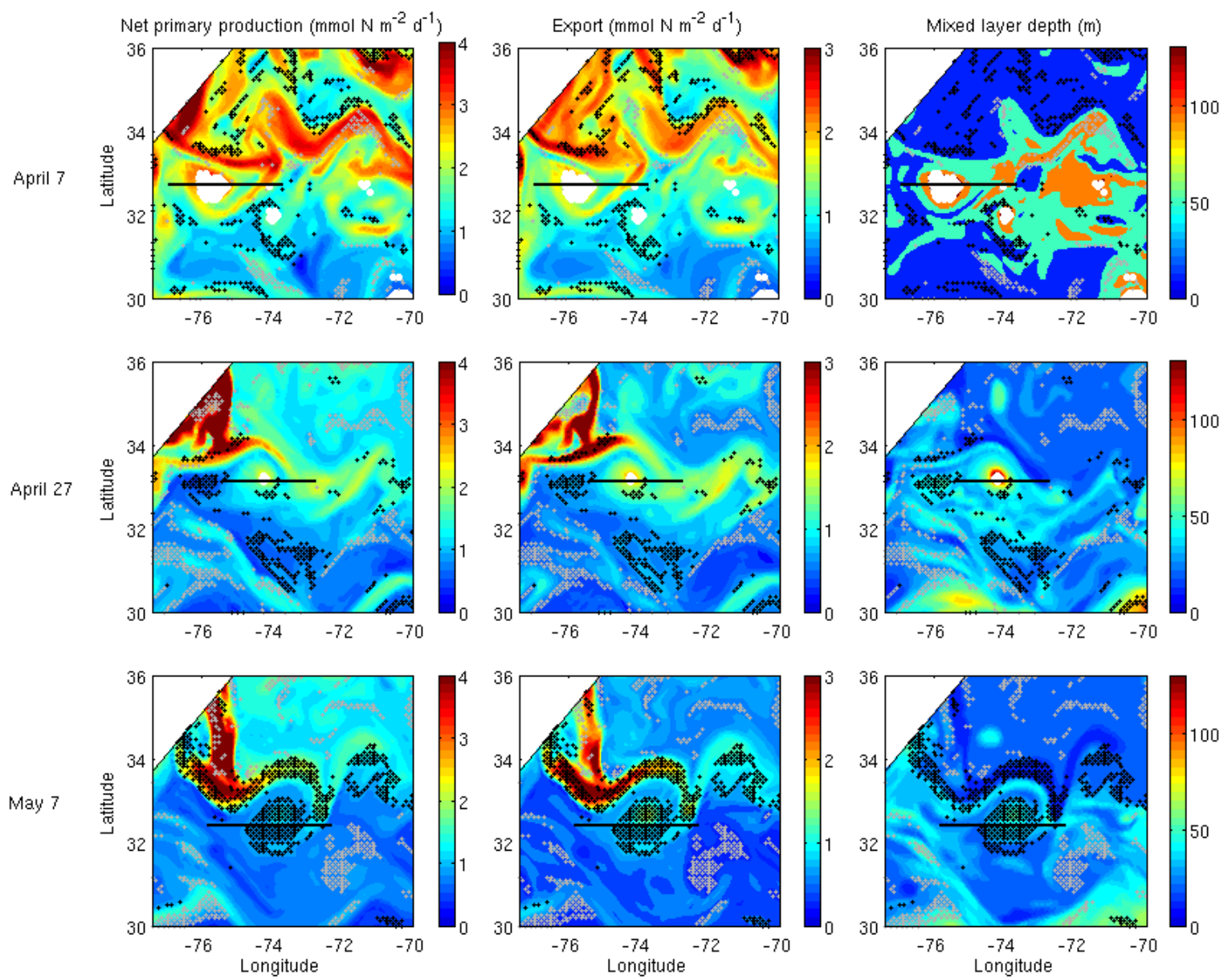

Figure 4. Zoomed-in view of a mesoscale export event. Net primary production (left column), export (middle column), and mixed layer depth (right column) on April 7 (top row), 27 (middle row), and May 7 (bottom row). Extrema in the export versus NPP relationship (binned at increments of $0.5 \mathrm{~mol} \mathrm{~N} \mathrm{~m}^{-2} \mathrm{~d}-1$ ) are shown in black (highest 10\%) and gray (lowest $10 \%$ ). Areas where the mixed layer depth exceeds the euphotic zone depth $(135 \mathrm{~m})$ are indicated in white. Solid black lines indicate the locations of the cross sections shown in Figure 4. 

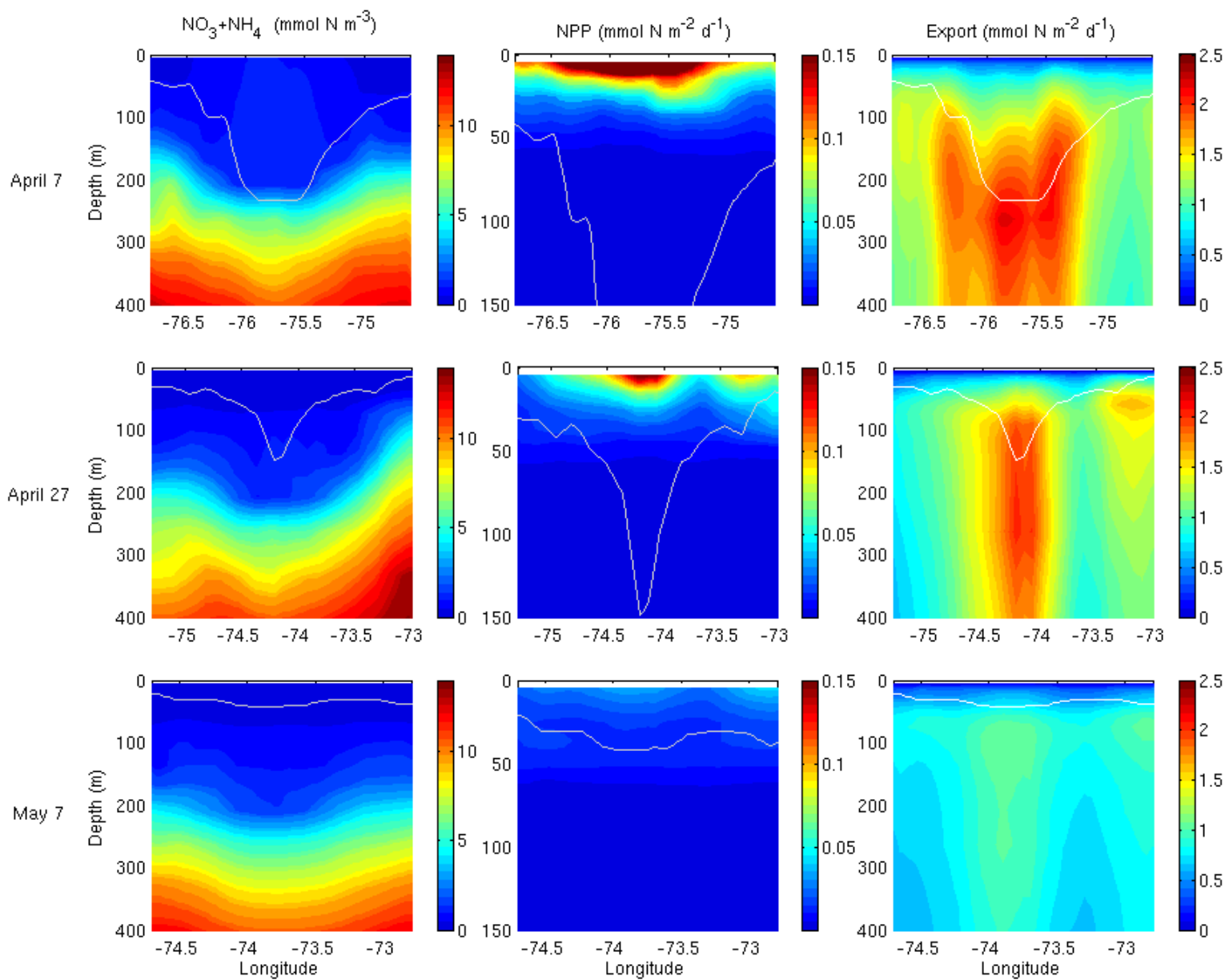

Figure 5. Cross sections of nitrate plus ammonium (left column), net primary production (middle column), and export (right column) on April 7 (top row), 27 (middle row), and May 7 (bottom row). The thin white line in each panel indicates the depth of the mixed layer. Locations of the cross sections for each date are shown as solid black lines in Figure 4. Note the shallower vertical scale of the right column. 